\title{
Analisa Profil Bandwidth Jaringan Copper, Fiber Optik and Migrasi Serta and Loss Link Budget Di Pt Telkom Kediri
}

\author{
Indra Hadi ${ }^{1}$, Riska Nurtantyo Sarbini ${ }^{2}$, Harso Kurniadi ${ }^{3}$ \\ ${ }^{1,2,3}$ Fakultas Teknik Elektro, Universitas Islam Kadiri \\ E-mail: 1indrahadimustofa.86@gmail.com, ${ }^{2}$ riskanurtantyosarbini@gmail.com, \\ 3harsok006@gmail.com
}

\begin{abstract}
Abstrak - Dalam hal layanan indihome 3P jaringan copper tidak mampu mengirim data internet yang maksimal $</=3$ Mbps maka dari itu dimigrasikan ke jaringan fiber optik yang mengirimkan bandwidth sampai $>100 \mathrm{Mbps}$. Rata-rata bandwidth jaringan copper upload 0,62 dan download 3,28 Mbps, serta jaringan fiber optik untuk upload 2,57 Mbps dan upload 11,62 Mbps, serta migrasi upload 7,01Mbps dan download 10,73 Mbps Attenuation atau redaman jaringan copper upload 16,82 dBm dan download 33,77 dBm serta jaringan fiiber optik atau migrasi redaman upload 2,44dBm dan download $-20,34$ dBm. Kabel fiber optik dalam pengiriman data melalui gelombang upload $1310 \mathrm{~nm}$, download $1490 \mathrm{~nm}$, streaming $1550 \mathrm{~nm}$ dengan loss link budget $</=-28$ dBm. Rata-rata yang didapat dari Attenuation rate jaringan copper, fiber optik dan migrasi terdapat penurunan kualitas jaringan coppoer yang rata-rata attenuation rate yaitu di upload $20 \mathrm{dBm}$ dan download 39 dBm dengan asumsi semankin besar nilai attenuation rate semakin baik di kisaran sampai 60 dBm dan fiber optik tetap stabil dikisaran upload 2 dBm dan Download -20 dBm. Rata-rata attainable rate jaringan copper, fiber optik dan migrasi kemampuan dari jaringan untuk dilewati oleh bandwidth copper upload 1.06 dan download 10.7, fiber optik upload 1073 dan download 2424 Mbps, serta migrasi upload 1007 Mbps dan download 2291 Mbps
\end{abstract}

Kata Kunci -- Copper, Optical Fiber, Migration, Bandwidth, Loss Link Budget.

\begin{abstract}
In the case of $3 P$ indihome copper network services are not able to send maximum internet data $</=3 \mathrm{Mbps}$ and therefore are migrated to fiber optic networks that transmit bandwidth up to $>100 \mathrm{Mbps}$. Average copper network upload bandwidth is 0.62 and download is $3.28 \mathrm{Mbps}$, and fiber optic network for upload is $2.57 \mathrm{Mbps}$ and upload is $11.62 \mathrm{Mbps}$, migration migration is 7.01 Mbps and download is 10.73 Mbps Attenuation or network attenuation copper uploads $16.82 \mathrm{dBm}$ and $33.77 \mathrm{dBm}$ downloads and optical fiiber networks or damping migration $2.44 \mathrm{dBm}$ uploads and $-20.34 \mathrm{dBm}$ downloads. Fiber optic cable in sending data via upload wave $1310 \mathrm{~nm}$, download $1490 \mathrm{~nm}$, streaming $1550 \mathrm{~nm}$ with a loss link budget $</=-28 \mathrm{dBm}$. The average obtained from the attenuation rate of copper, optical fiber and migration networks is that there is a decrease in the quality of the coppoer network with an average attenuation rate that is uploaded at $20 \mathrm{dBm}$ and downloading $39 \mathrm{dBm}$ with the assumption that the greater the attenuation rate is better in the range of up to $60 \mathrm{dBm}$ and fiber optics remain stable in the $2 \mathrm{dBm}$ upload range and $-20 \mathrm{dBm}$ download. Average attainable rate of copper network, optical fiber and migration ability from the network to be passed by copper bandwidth upload 1.06 and download 10.7, optical fiber upload 1073 and download $2424 \mathrm{Mbps}$, and migration upload $1007 \mathrm{Mbps}$ and download $2291 \mathrm{Mbps}$
\end{abstract}

Keywords-Copper, Optical Fiber, Migration, Bandwidth, Loss Link Budget. 


\section{PENDAHULUAN}

Semakin pesat perkembangan teknologi pada setiap waktu, terutama pada bidang telekomunikasi, mulai dari data internet, telephone dan tv kabel. Proses menjalankan layanan layanan tersebut, dibutuhkan bandwidth yang memadai serta akses internet dengan kecepatan yang tinggi. Oleh karena itu media jaringan tembaga pada era digital sudah tidak mampu lagi untuk menyediakan data internet yang stabil cepat dan tahan terhadap gangguan maka dari itu jaringan ditransmigrasikan ke serat fiber optik agar dapat memenuhi kebutuhan tersebut. Agar layanan layanan tersebut dapat dinikmati oleh orang - orang dirumah yang disebut juga dengan Indihome, maka para penyedia jasa layanan telekomunikasi menawarkan layanan Fiber To The Home (FTTH).

Sesuai uraian diatas, maka permasalahan yang akan diangkat dalam penelitian ini dapat dirumuskan sebagai berikut bagaimana mengambil data profil bandwidth jaringan tembaga dan fiber optik dan Bagaimana melakukan analisa yang tepat tentang line rate, attenuation rate, attainable rate pada jaringan copper, fiber optik dan migrasi dan loss link budget pada topologi fiber optik. Dalam hal ini untuk melakukan pembatasan masalah yang akan diteliti sebagai berikut wilayah operasi jaringan telekomunikasi di PT Telkom Kediri. Periode pada bulan November 2018 pengambilan data jaringan tembaga dan fiber optik dengan batasan sinyal loss link budget serta profil internet dan jumlah layanan. Berdasarkan rumusan masalah yang telah diuraikan sebelumnya, maka tujuan dari penelitian yaitu membuktikan bahwa pergantian jaringan copper ke fiber atau migrasi dapat meningkatkan Bandwidth Internet dan layanan tambahan (IPTV), Telephone dengan loss link bidget yang terukur.

Jaringan Lokal Tembaga Jarlokat atau jaringan local tembaga (copper) merupakan media akses yang menyalurkan informasi menggunakan kabel tembaga yang terhubung antara central dengan perangkat Main Distribution Frame (MDF) menuju pelanggan dengan perangkatnya Rumah Kabel (RK) lalu selanjutnya Distribution Point (DP).

Jaringan berbasis fiber optik adalah jaringan telekomunikasi yang dalam pengoprasiannya menggunakan kabel serat optik untuk mendistribusikan informasi atau data berkecepatan cahaya sehingga data yang kirim sangat cepat dan stabil.

Fiber optik dalam prinsip kerjanya adalah sebagai media transfer data yang dimulai dari perangkat aktif OLT (Optical Line Terminal) yaitu perangkat yang mengubah sinyal elektrik atau listrik menjadi informasi optik dengan panjang gelombang 1310 untuk upload, 1490 untuk download dan 1550 untuk vidio, kemudian dilewatkan pada jaringan fiber optik ke perangkat passive spliter (pemecah atau pembagi informasi sinyal optik) sampai akhirnya di ONT pada ujung jaringan juga termasuk perangkat aktif yang berfungsi sebagai pengubah sinyal optik menjadi sinyal elektrik (Wifi, Internet, Telephone, TV Kabel)

\section{METODE PENELITIAN}

Metode perancangan yang digunakan dalam penelitian ini sebagai beikut. 


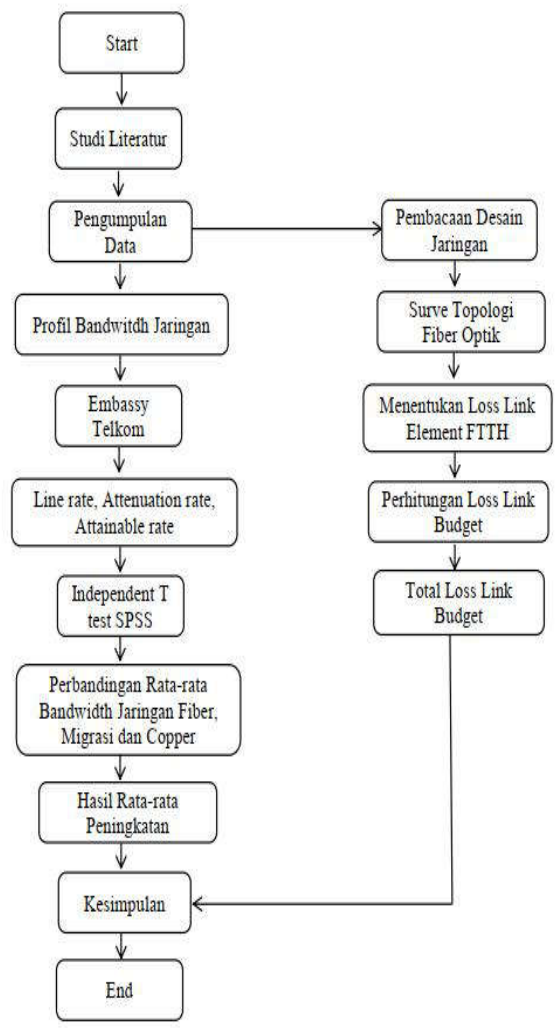

Gambar 1. Metodelogi Penelitian

\section{HASIL DAN IMPLEMENTASI}

Pengambildan data dari embassy dengan memasukan nomor layanan internet pelanggan maka akan muncul tampilan seperti berikut :

Nomor nomor speedy

Domain telkomnes

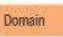

MAC Address

Paket isiska

Paket Radius Paket PCRF

Profile Referensi

Status Pelanggan

Port Binding

R2BB

Comments

No Telepon

EQN

Datek

Nama

Alamat

Ukur

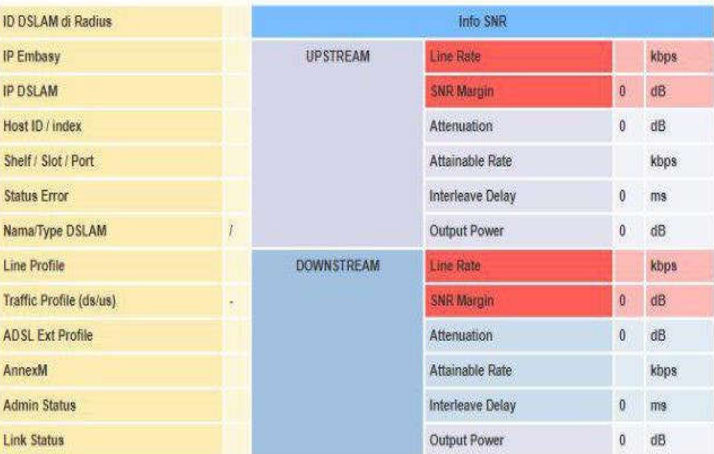

Gambar 2. Embassy

\subsection{Profil Bandwidth Line rate}

Rata-rata profil bandwidth line rane dari 30 pelanggan PT TELKOM dari jaringan copper, fiber optik dan migrasi: 
Tabel 1. Profil Bandwidth

\begin{tabular}{|c|c|c|}
\hline Jaringan & Profil & Bandwidth \\
\hline Copper & Upload & 0.62 \\
\hline Copper & Download & 3.28 \\
\hline Fiber Optik & Upload & 2.57 \\
\hline Fiber & Download & 11.62 \\
\hline Migrasi & Upload & 7.01 \\
\hline Migrasi & Download & 10.73 \\
\hline
\end{tabular}

Perhitungan perbandingan rata-rata line rate fiber copper dan migrasi copper sebagai berikut:

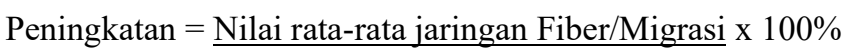

Nilai rata-rata jaringan Copper

Tabel 2. Presentase Peningkatan

\begin{tabular}{|c|l|l|c|}
\hline No & Line Rate jaringan & \multicolumn{1}{|c|}{ Profil } & Peningkatan \\
\hline \multirow{2}{*}{1} & \multirow{2}{*}{ Fiber dan Copper } & Upload & $414 \%$ \\
\cline { 3 - 4 } & & Download & $354 \%$ \\
\hline \multirow{2}{*}{2} & \multirow{2}{*}{ Migrasi dan Copper } & Upload & $1131 \%$ \\
\cline { 3 - 4 } & & Download & $327 \%$ \\
\hline
\end{tabular}

\subsection{Profil Attenuation Rate}

Rata-rata attenuation rate dengan jumlah 30 pelanggan dari jaringan copper fiber optik dan migrasi adalah sebagai berikut:

Tabel 3. Rata-rata Rate

\begin{tabular}{|c|c|c|}
\hline Jaringan & Keterangan & Rata - rata $(\mathrm{dBm})$ \\
\hline \multirow{2}{*}{ Copper } & Upload & 16,82 \\
\cline { 2 - 3 } & Download & 33,67 \\
\hline \multirow{2}{*}{ Fiber Optik } & Upload & 2,44 \\
\cline { 2 - 3 } & Download & $-20,34$ \\
\hline Migrasi & Upload & 2,37 \\
\cline { 2 - 3 } Fiber Optik & Download & $-20,51$ \\
\hline
\end{tabular}

\subsection{Profil Attainable Rate}

Rata-rata attainable rate dengan jumlah 30 pelanggan dari jaringan copper fiber optik dan migrasi adalah sebagai berikut:

Tabel 4. Presentase Peningkatan Rate

\begin{tabular}{|l|l|l|l|}
\hline Jaringan & Keterangan & Rerata & Peningkatan \\
\hline \multirow{2}{*}{ Fiber Optik } & Upload & 1073 & $1013 \%$ \\
\cline { 2 - 4 } & Download & 2424 & $22631 \%$ \\
\hline \multirow{2}{*}{$\begin{array}{l}\text { Migrasi Fiber } \\
\text { Optik }\end{array}$} & Upload & 1007 & $950 \%$ \\
\cline { 2 - 4 } & Download & 2291 & $21410 \%$ \\
\hline
\end{tabular}

\subsection{Menentukan Jalur atau Desain Jaringan}

Penentuan jalur pada topologi ini sangat penting untuk mengetahui segmen mulai dari In Side Plant dan Out Side Plant, untuk itu dipilih jalur ODC-KDI-FAY/01-06 seperti gambar dibawah ini: 


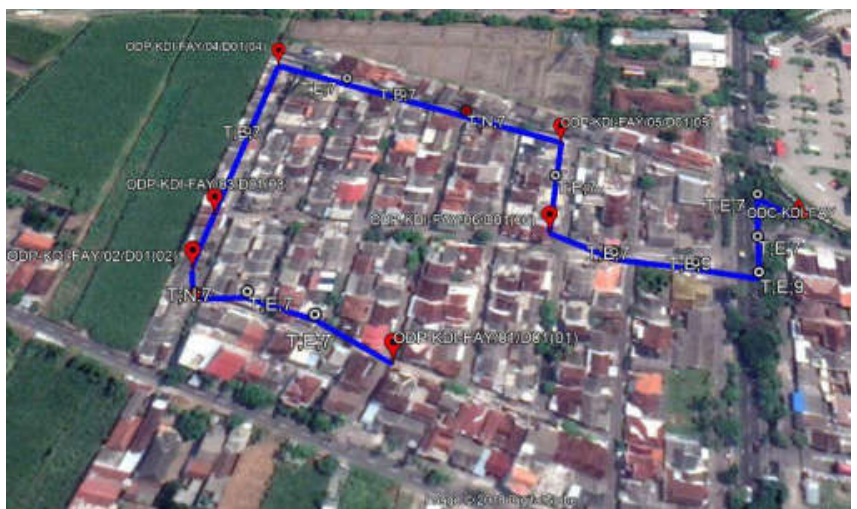

Gambar 3. Gambar Pembangunan Jaringan Fiber Optik

Dalam melakukan analisa perhitungan loss link budget menggunakan rumus seperti berikut :

Tabel 5. Analisa Loss Link

\begin{tabular}{|c|c|c|c|c|c|}
\hline Perangkat & Simbol & Nilai & Jumlah & Satuan & Keterangan \\
\hline OLT & $\mathrm{Pt}$ & 2.3 & 1 & $\mathrm{Bm}$ & ISP \\
\hline FTM & & & & & \multirow{5}{*}{ ISP } \\
\hline \multirow[t]{2}{*}{ EA } & $\alpha \mathrm{s}$ & 0.02 & 1 & B & \\
\hline & $\alpha \mathrm{c}$ & -0.25 & 1 & B & \\
\hline \multirow[t]{2}{*}{$\mathrm{OA}$} & $\alpha \mathrm{s}$ & -0.02 & 1 & $\mathrm{~B}$ & \\
\hline & $\alpha \mathrm{c}$ & -0.25 & 1 & B & \\
\hline UC Chamber & $\alpha \mathrm{s}$ & 0.02 & 1 & B & ISP \\
\hline $\begin{array}{ll}\text { Kabel } \\
\text { Feeder }\end{array}$ & L & 0.35 & 4 & $\mathrm{~m} / \mathrm{dB}$ & OSP \\
\hline hole UC Hand & $\alpha \mathrm{s}$ & 0.02 & 1 & B & OSP \\
\hline \multirow[t]{3}{*}{ ODC } & $\alpha \mathrm{s}$ & 0.02 & 1 & B & \multirow{3}{*}{ OSP } \\
\hline & $\alpha \mathrm{c}$ & 0.25 & 1 & $\mathrm{~B}$ & \\
\hline & $\operatorname{Sp}(1: 4)$ & 7.25 & \multicolumn{2}{|c|}{$1 \mathrm{~B}$} & \\
\hline Distribusi & $\mathrm{L}$ & 0.35 & 1 & $\mathrm{~m} / \mathrm{dB}$ & OSP \\
\hline \multirow[t]{3}{*}{ ODP } & $\alpha \mathrm{s}$ & 0.02 & 1 & $\mathrm{~B}$ & \multirow{3}{*}{ OSP } \\
\hline & $\alpha \mathrm{c}$ & 0.25 & 1 & $\mathrm{~dB}$ & \\
\hline & $p(1: 8)^{S}$ & 10.38 & 1 & B & \\
\hline Dropcore & $\mathrm{L}$ & 0.35 & 0.5 & $\mathrm{~m} / \mathrm{dB}$ & OSP \\
\hline Roset & $\alpha \mathrm{s}$ & 0.02 & 1 & $\mathrm{~B}$ & ISP \\
\hline
\end{tabular}

$\alpha$ total $=$ L. $\alpha$ serat $+\mathrm{Nc} . \alpha \mathrm{c}+\mathrm{Ns} . \alpha \mathrm{s}+\mathrm{Sp}$

atotal $=(6,5 \cdot 0,35)+(4 \cdot 0,25)+(7 \cdot 0,02)+7,25+10,38$

$=2,27+1+0,14+17,63$

$=21,74 \mathrm{dBm}$

$\operatorname{Pr} \quad=\mathrm{Pt}-$ atotal

$=2.44-21,04$

$=-18,60 \mathrm{dBm}$

$\mathrm{M}=\{(\mathrm{Pt}-\operatorname{Pr}($ Sensitivitas $)\}-$ atotal $-\mathrm{SM}$

$=\{(2,44-(-18,60)\}-(21,04-6)$

$=21,04-15,04$

$=6 \mathrm{dBm}$ 


\section{SIMPULAN}

Rata-rata pada jaringan copper, fiber optik dan migrasi terdapat peningkatan line rate fiber dan copper upload $414 \%$, download $354 \%$ dan line rate migrasi dan copper upload $1131 \%$ dan download $417 \%$. Rata-rata yang didapat dari Attenuation rate jaringan copper, fiber optik dan migrasi terdapat penurunan kualitas jaringan coppoer yang rata-rata attenuation rate yaitu di upload $20 \mathrm{dBm}$ dan download $39 \mathrm{dBm}$ dengan asumsi semankin besar nilai attenuation rate semakin baik di kisaran sampai $60 \mathrm{dBm}$ dan fiber optik tetap stabil dikisaran upload $2 \mathrm{dBm}$ dan Download $-20 \mathrm{dBm}$. Rata-rata attainable rate jaringan copper, fiber optik dan migrasi kemampuan dari jaringan untuk dilewati oleh bandwidth copper upload 1.06 dan download 10.7, fiber optik upload 1073 dan download $2424 \mathrm{Mbps}$, serta migrasi upload 1007 Mbps dan download $2291 \mathrm{Mbps}$.

\section{SARAN}

Berikut adalah beberapa saran yang diharapkan mampu menambah penyempurnaan penelitian ini untuk produk multimedia media pembelajaran pengenalan hewan berbasis augmented reality $t$ yaitu:

a. Media pembelajaran perlu ditambahkan leaderboard untuk mengetahui prospek kemajuan $u$ ser yang menggunakan.

b. Menambahkan level kesulitan dalam pengerjaan soal.

\section{DAFTAR PUSTAKA}

[1] A. Sofian and M. Ariyanti, "Pengaruh Quality Of Service Terhadap Brand Equity Indihome Di Bandung," eProceedings Manag., vol. 3, no. 2, 2016.

[2] N. Duwilaa, S. Santosa, and S. Hamza, "Analisis Kualitas Jaringan Fiber Optik Layanan Indihome Pada PT. Telkom di Wilayah Kota Ternate Tengah,” J-TIFA, vol. 1, no. 1, pp. 34-42, 2018.

[3] I. G. D. Prastiwi, S. Sugito, and A. R. Bermano, "Perancangan Jaringan Akses Fiber To The Home (ftth Dengan Teknologi Gigabit Passive Optical Network (gpon) Di Private Village, Cikoneng," eProceedings Eng., vol. 2, no. 3, 2015.

[4] PT Telkom Indonesia, "Pedoman Jaringan FTTH,” Pedoman Jar. FTTH PT Telkom Indones., vol. 1.0, no. 1.0, 2013.

[5] P. Paliwan, A. Hambali, and H. Hafiddudin, "Analisis Rekonfigurasi Jaringan Hybrid Optik-tembaga Menjadi Jaringan Optik,” eProceedings Eng., vol. 3, no. 3, 2016. 